水文・水资源学 会誌

J. Japan Soc. Hydrol \& Water Resour. Vol. 7. No. 1 (1994)

\title{
飽和水蒸気圧の計算誤差
}

\section{Errors in Calculation of Satulation Vapor Pressure}

$\begin{array}{ll}\text { 菅原広史* } & \text { (東北大学理学部) } \\ \text { Hirofumi SUGAWARA } & \text { Geophysical Institute, Tohoku University } \\ \text { 近藤純正* } & \\ \text { Junsei KONDO } & \end{array}$

Keywords: Satulation vapor pressure, Surface heat balance

キーワード：鼠和水蒸気圧，地表面熱収支

I .はじめに

飽和水蒸気圧を温度の関数として表す式は, 現在 色々なものが知られており，どれを使用すべきか迷 うことが多い。つまり，それぞれの式による值がど れほど違うのか, 大量のデー夕処理にあたって計算 時間はどれが最も短いか，さらに地表面の熱収支の 計算にどれほどの違いが生じるかという問題がある。 前 2 者の問題に対しては過去に様々な比較が発表さ れている (Gibbins, 1990; Flatau et al, 1992).ここ では主に 3 番目の問題を取り上げる. まず代表的な 式を比較し，その差が地表面の熱収支にどれほど影 製するかを調べ,さらに飽和水蒸気圧の微係数につ いても檢郡する。

\section{II. 飽和水弥父圧の比較}

比較した式は一般に使われている以下のものであ る. 温度 $\mathrm{T}$ 単位は ${ }^{\circ} \mathrm{C}$, 飽和水蒸気压 $e_{s a t}$ の単位は $\mathrm{hPa}$ とする.式(1)，(2)はある温度篹囲を対象とした近 似式であり，その範囲を括弧内に示した， $e_{\text {sat }}$ には， 水面上と氷面上に対する 2 種類があるが，ここでは 水面上に対する値について検討する。

Lowe (1977) の式: $\left(-50 \sim 50^{\circ} \mathrm{C}\right)$

$$
e_{s a t}=A_{0}+T\left(A_{1}+T\left(A_{2}+T\left(A_{s}+T\right.\right.\right.
$$

$$
\left.\left.\left.\left(A_{4}+T\left(A_{5}+A_{6} T\right)\right)\right)\right)\right)
$$

$A_{0}=6.107799961$

$A_{1}=4.436518521 \times 10^{-1}$

$A_{2}=1.428945805 \times 10^{-2}$

$A_{3}=2.650648471 \times 10^{-4}$

$A_{4}=3.031240396 \times 10^{-6}$

$A_{5}=2.034080948 \times 10^{-8}$

$A_{6}=6.136820929 \times 10^{-11}$

Tetens (1930) の式 :

$$
\begin{aligned}
& e_{s a t}=6.1078 \times 10^{K} \\
& K=\frac{(7.5 T)}{(T+237.3)}
\end{aligned}
$$

Bolton (1980) の式：(-35 35 $5^{\circ} \mathrm{C}$

$$
e_{s a t}=6.112 \exp \frac{17.67 T}{T+243.5}
$$

これらをー50〜100 $\mathrm{C}$ 範囲で計算し, Smithsonian Tables(List, 1966) と比較した。この表の数値はGoff -Gratchの式に基づき作成されており，(1)〜3)式を 導出するもとになったものであるが, Goff-Gratch の式も近似式であり，けっしてこれが真値であるわ けではない.しかし，最近の精密測定に基づくWexler(1976)の式と比較して差がわずかであるので, こ こではSmithsonian Tablesを基準にして比較する. 結果は衰一1 と図一 1 に示す。 
表一1 Smithsonian Tablesによる的水蒸気圧 （基準値）と各式の比較。 差 $=$ (各式の値 $)-$ (基藻值 $)$

\begin{tabular}{|c|c|c|c|c|c|c|c|}
\hline \multirow[b]{2}{*}{$\begin{array}{l}\text { 温度 } \\
\left({ }^{\circ} \mathrm{C}\right)\end{array}$} & \multirow[b]{2}{*}{$\begin{array}{l}\text { 莹萑值 } \\
(\mathrm{hPa})\end{array}$} & \multicolumn{6}{|c|}{ 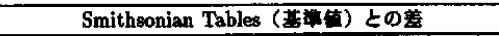 } \\
\hline & & $\begin{array}{l}\text { Lowe } \\
\text { (hPa) }\end{array}$ & $\%$ & $\begin{array}{l}\text { Tetens } \\
(\mathrm{hPa})\end{array}$ & $\%$ & $\begin{array}{l}\text { Bolton } \\
(\mathrm{hPa})\end{array}$ & $\%$ \\
\hline-50 & 0.0635 & -0.0002 & -0.293 & -0.0027 & -4.286 & 0.0000 & 0.108 \\
\hline-40 & 0.1891 & 0.0000 & 0.026 & -0.0049 & -2.576 & 0.0005 & 0.252 \\
\hline$-\mathbf{3 0}$ & 0.5088 & -0.0010 & -0.203 & -0.0070 & -1.382 & 0.0016 & 0.305 \\
\hline-20 & 1.2540 & -0.0001 & -0.011 & -0.0078 & -0.620 & 0.0034 & 0.271 \\
\hline-10 & 2.8627 & 0.0008 & 0.028 & -0.0056 & -0.196 & 0.0050 & 0.175 \\
\hline $\mathbf{0}$ & 6.1078 & 0.0000 & 0.000 & 0.0000 & 0.000 & 0.0042 & 0.069 \\
\hline 10 & 12.272 & -0.001 & -0.010 & 0.00 & 0.056 & -0.000 & \\
\hline 20 & 23.373 & -0.002 & -0.008 & 0.008 & 0.034 & -0.004 & -0.015 \\
\hline 30 & 42.430 & -0.001 & -0.002 & -0.004 & -0.009 & 0.026 & 0.061 \\
\hline 40 & 73.777 & -0.002 & -0.002 & -0.030 & -0.0040 & 0.172 & 0.233 \\
\hline 50 & 123.40 & 0.01 & 0.006 & -0.05 & -0.0040 & 0.62 & 0.506 \\
\hline 60 & 199.26 & & 0.064 & 0.04 & 0.020 & 1.78 & 0.893 \\
\hline 70 & 311.69 & 0.60 & 0.191 & 0.42 & 0.136 & 4.30 & 1.379 \\
\hline 80 & 473.67 & 2.00 & 0.421 & 1.49 & 0.315 & 9.30 & 1.964 \\
\hline 90 & 701.13 & 5.49 & 0.783 & 3.91 & 0.557 & 18.52 & 2.642 \\
\hline 100 & 1013.25 & 13.08 & 1.291 & 8.69 & 0.857 & 34.46 & 3.401 \\
\hline
\end{tabular}

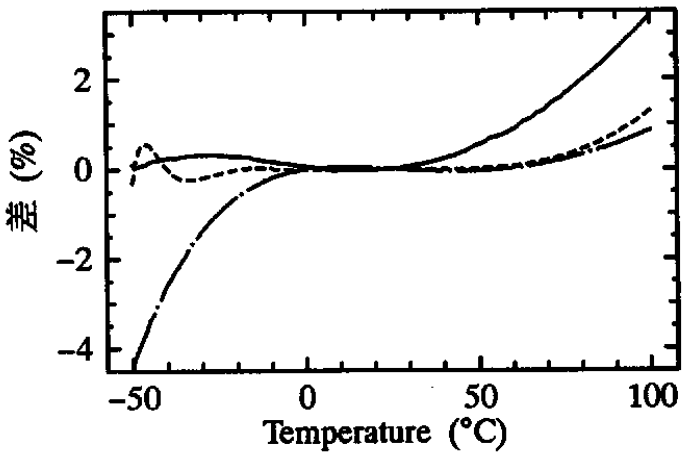

図一1飽和水蒸気圧についての各式とSmithsonian Tablesとの差. 実線：Boltonの式, 破線：Loweの式, 1 点鎖線：Tetensの式

图一 1 を見ると，ほほ全域で相対誤差 $1 \%$ 以下， 大きくても $4 \%$ 程度であることがわかる. Loweの 式は計算時間が短いという特徵があり, Tetensの式 とBoltonの式は表現形式が簡単であるという特幑 がある。

\section{III. 地表面熱収支の計算における館和水蒸 気圧の式の逞い}

前節で各式を比較した結果, どの式による值も大 きな差がないことがわかった. それでは地表面の熱 収支において飽和水蒸気圧の誤差が, 結果にどれほ ど影響するのかを調べてみよう。

気温 $T$, 比湿 $q$, 地表面での蒸発効率 $\beta$ を仮定し, 地表面温度 $T_{s}$, 顕熱輸送量 $H$, 潜熱輸送量 $l E$ の 3 つ
表一2 地衰面の繁収支に対する $\mathrm{e}_{s a t}$ の敏惑度共通 条件 $R^{\prime}=(1-\alpha) S \downarrow+L \downarrow=1000$ $\left(\mathrm{Wm}^{-2}\right)$, 相対湿度 $=50 \%$, 気温 $T=40^{\circ} \mathrm{C}$ 条件 1: $C_{H} U=0.002(\mathrm{~m} / \mathrm{s}), \beta=0.05$ 条件 $2: C_{H} U=0.002(\mathrm{~m} / \mathrm{s}), \beta=1.0$ 条件 $3: C_{H} U=0.04(\mathrm{~m} / \mathrm{s}), \beta=0.05$ 条件 $4: C_{H} U=0.04(\mathrm{~m} / \mathrm{s}), \beta=1.0$

\begin{tabular}{|c|c|c|c|c|}
\hline 条件 & $e_{\text {sat }}$ の式 & 地表面温度 $T_{s}$ & 䫓熱 $H$ & 潜熱 $l E$ \\
\hline & & ${ }^{\circ} \mathrm{C}$ & $W / m^{2}$ & $W / m^{2}$ \\
\hline \multirow[t]{3}{*}{ 策件 1} & Tetens & 76.15 & 81.65 & 74.26 \\
\hline & Lowe & 76.14 & 81.63 & 74.26 \\
\hline & Bolton & 76.06 & 81.45 & 75.25 \\
\hline \multirow[t]{3}{*}{ 条件 2} & Tetens & 51.43 & 25.82 & 344.9 \\
\hline & Lowe & 51.43 & 25.82 & 344.9 \\
\hline & Bolton & 51.36 & 25.66 & 345.6 \\
\hline \multirow[t]{3}{*}{ 条件 3} & Tetens & 44.75 & 214.6 & 206.1 \\
\hline & Lowe & 44.75 & 214.6 & 206.1 \\
\hline & Bolton & 44.74 & 214.1 & 206.8 \\
\hline \multirow[t]{3}{*}{ 策件 4} & Tetens & 32.39 & -343.8 & 850.5 \\
\hline & Lowe & 32.39 & -343.8 & 849.8 \\
\hline & Bolton & 32.40 & -343.3 & 849.1 \\
\hline
\end{tabular}

を末知数として求めることにする. 地表面での熱収支式は

$$
(1-\alpha) S \downarrow+L \downarrow=H+l E+G+\sigma T_{s}^{4}
$$

である.ただし $S \downarrow$ は日射量, $L \downarrow$ は下向き大気放射

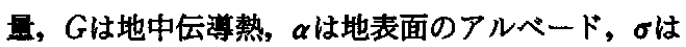
ステファン・ボルツマン定数である。ここで,

$$
R^{\prime}=(1-\alpha) S \downarrow+L \downarrow-G
$$

とすると式(4)は次のようになる.

$$
R^{\prime}=H+l E+\sigma T_{s}^{4}
$$

ここでHとlEは次のバルク式で表される.

$$
\begin{aligned}
& H=\rho c_{P} C_{H} U\left(T_{s}-T\right) \\
& l E=l \rho C_{H} U \beta\left(q_{s a t}\left(T_{s}\right)-q\right)
\end{aligned}
$$

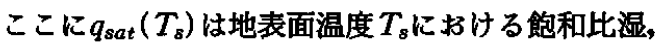
$C_{H} U$ は交換係数, $c_{P}$ は空気の比熱, $\rho$ は空気の密 度, lは蒸発の潜熱である. $q_{s a t}\left(T_{s}\right)$ と $e_{s a t}\left(T_{s}\right)$ とのあ いだにはpを大気圧とすれば

$$
q_{s a t}\left(T_{s}\right)=\frac{0.622 e_{s a t}\left(T_{s}\right)}{p-0.378 e_{s a t}\left(T_{s}\right)}
$$

の関係がある.

式(6)(7)(8)より $R^{\prime}, C_{H} U, \beta, T, q$ を元て $T_{s}$, $H ， l E$ を解くことができる（たとえばKondo and Watanabe, 1992)。ここで簡単化のため $G=0$ とし, いろいろな条件で計算した結果を表一 2 に示す，条 件はできるだけ $T_{s}$ が大きくなる $\left(e_{s a t}\right.$ の違いが出る)よ うにした。これによると一番違いの大きかった条件 
$1\left(T_{s} \simeq 76^{\circ} \mathrm{C}, e_{s a t}\right.$ の差が $1 \%$ 程度) のときでも， $T_{s}$ の 結果に出る差は $0.09^{\circ} \mathrm{C}$, 潜熱で $1.1 \mathrm{~W} / \mathrm{m}^{2}$ 程度であ る.よって飽和水蒸気圧の式にどれを使っても結果 には実質上ほとんど影響がないことがわかる。

\section{IV . 地表面熱収支の近似郡算の場合}

実際問題に適用する際に, 式(6)(7)(8)を線形化して 熱収支式を近似式で表すことがある（たとえば近藤・ 桑形，1992）。

$$
\begin{aligned}
& \sigma T_{s}^{4} \simeq \sigma T^{4}+4 \sigma T^{3}\left(T_{s}-T\right) \\
& q_{s a t}\left(T_{s}\right) \simeq q_{s a t}(T)+\left(\frac{d q_{s a t}}{d T}\right)_{T}\left(T_{s}-T\right)
\end{aligned}
$$

とすると, 式(6)〜 (9)から $T_{s}$ は次のような近似式で表 される.

$$
\begin{aligned}
& T_{s}-T \simeq \frac{R^{\prime}-\sigma T^{4}-l \rho C_{H} U \beta\left(q_{s}-q\right)}{4 \sigma T^{3}+\rho c_{p} C_{H} U+l \rho C_{H} U \beta \Delta} \\
& q_{s}=\frac{0.622 e_{\text {sat }}(T)}{p-0.378 e_{s a t}(T)} \\
& \Delta=\left(\frac{\left.d q_{s a t}\right)_{T}}{d T}\right)_{T} \\
& \frac{d q_{\text {sat }}}{d T}=\frac{0.622 p}{\left(p-0.378 e_{\text {sat }}\right)^{2}} \frac{d e_{\text {sat }}}{d T}
\end{aligned}
$$

ただし $q_{\text {sat }}(T)$ は気温Tにおける飽和比湿である.こ のとき $\frac{d e_{\text {sat }}}{d T}$ を計算する必要がでてくる.これを計算 する方法には次の 2 つがある.

1. 各式 $(1,2,3)$ をそのまま温度について微 分する方法。

2. クラウジウスークラペイロンの式を使う方法 である. クラウジウスークラペイロンの式は

$$
\frac{d e_{s a t}}{d T}=\frac{l e_{s a t}}{R_{w} T^{2}}
$$

ここでR $R_{w}$ は水蒸気の気体定数, $T$ の単位は $K$. また Lowe (1977) は $\frac{d e_{\text {sat }}}{d T}$ 求める式として次式を表して いる.

$$
\begin{aligned}
\quad \frac{d e_{\text {sat }}}{d T}=B_{0}+T\left(B_{1}+T\left(B_{2}+T\left(B_{3}+T\right.\right.\right. \\
\left.\left.\left.\quad\left(B_{4}+T\left(B_{5}+B_{6} T\right)\right)\right)\right)\right) \\
B_{0}=4.438099984 \times 10^{-1} \\
B_{1}=2.857002636 \times 10^{-2} \\
B_{2}=7.938054040 \times 10^{-4} \\
B_{3}=1.215215065 \times 10^{-5} \\
B_{4}=1.036561403 \times 10^{-7} \\
B_{5}=3.532421810 \times 10^{-10} \\
B_{6}=-7.090244804 \times 10^{-13}
\end{aligned}
$$

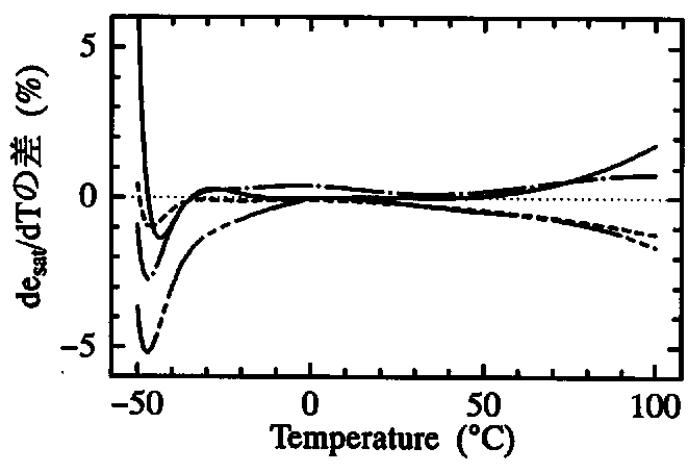

图一 $2 \frac{d e_{\text {sat }}}{d T}$ の比较. 実線：Loweの式(1)の微分と 式(17)の差, 破線：式(1)(16)と式(17)の差，1点 鎖線：Tetensの式(2)の微分と式(17)の差, 2 点銷線：式(2)(16)と式(17)の差.

图一2にはLoweの式とTetensの式を利用し，2 つの方法で求めた $\frac{d e_{\text {sat }}}{d T}$ の差について示した.

図一 2 を見ると差は常温域て $1 \%$ 以下，最大でも 数\%程度であることがわかる，III章より $e_{s a t}$ の值が $1 \%$ 程度変わっても熱収支にはほとんど影䡬がでな いことがわかった。 したがって，式(10)〜(14)のように 線形化した場合, どの方法で求めた $\frac{d e_{\text {sat }}}{d T}$ を使っても 熱収支はほとんど変化しないことがわかる.

なお補足として, 式(9)は分母第 2 項を無視して使 われることがある.これは温度が低いとき, $e_{\text {sat }}$ が大 気圧pより小さいとした近似である.この $q_{s a t}$ そのも のの近似の誤差を計算したところ, 温度が $40^{\circ} \mathrm{Cでは}$

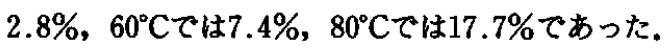
したがって温度が $60^{\circ} \mathrm{C}$ 以上になるとこの近似は精度 が悪いことが分かる。

\section{V.まとめ}

飽和水蒸気圧を表す各種実験式を比較し，その違 いが地表面の熱収支量にどれくらい影䔩するかを調 へた. その結果，実験式による違いは事実上無視て きることが分かった。

また $\frac{d e_{\text {sat }}}{d T}$ を計算する方法についても比較した。 こ れについても方法による違いは熱収支にはほとんど 影㺕しないことがかかった，そえゅえ，莫大な量の データ処理でなければ, 式の簡単なTetensの式(2)と 式(16)の利用で十分である。

\section{参考文献}

Bolton, D. (1980): The computation of equiva- 
lent potential temperature. Mon. Wea. Rev., 108, pp. 1046-1053

Flatau, P.J., R.L. Walko, and W.R. Cotton (1992): Polynomial fits to satulation vapor pressure. J. Appl. Meteor., 31, pp. 1507-1513

Gibbins, C.J. (1990): A survey and comparison of relationships for the determination of the saturation vapour pressure over plane surfaces of pure water and of pure ice. Ann. Geophys. Atmos. , 8, pp. 859-886

List, R.J. (1966): Smithsonian Meteorological Tabels. 6th, Revised, Ed. The Smithsonian Institution. pp. 347-353

Lowe, P.R. (1977): An approximating polynomial for the computation of saturation vapor pressure. J. Appl. Meteor., 16, pp. 100-103

Tetens, O. (1930): Über einige meteorologische Begriffe. Z. Geophys., 6, pp. 297-309

Wexler, A. (1976): Vapor pressure formulation for water in range 0 to $100^{\circ} \mathrm{C}, \mathrm{A}$ revision. $\mathrm{J}$. Res. NBS, 80(A), pp. 775-785

Kondo, J. and T. Watanabe (1992): Studies on the bulk transfer coefficients over a vegetated surface with a multilayer energy budget model. J. Atmos. Sci., 49, pp. 2183-2199

近藤純正・桑形恒男 (1992) : 日本の水文気象(1)放射 量と水面蒸発. 水文水資源学会誌, 5(2), pp. 13-27 (1993年 6 月15日受付, 1993年 8 月20日受理) 